\title{
Cervical elastography during pregnancy: clinical perspectives
}

\author{
This article was published in the following Dove Press journal: \\ International Journal of Women's Health \\ 21 April 2017 \\ Number of times this article has been viewed
}

\section{Malgorzata Swiatkowska- Freund Krzysztof Preis}

Department of Obstetrics, Medical University of Gdańsk, Gdańsk, Poland
Correspondence: Malgorzata

Swiatkowska-Freund

Department of Obstetrics, Medical

University of Gdańsk, ul. Kliniczna IA,

80-402 Gdańsk, Poland

Tel +48583493445

Fax +48583493416

Email malswi@gumed.edu.pl
Abstract: Uterine cervix is a part of the uterus responsible for maintaining pregnancy till term. As long as the cervix remains long and firm and its internal orifice (os) is closed, it can withstand enlargement of the uterine contents and resultant growing pressure. Mechanical properties of the cervix change during pregnancy; the cervix ripens prior to delivery, then effaces and dilates with contractions of the uterus. Ripening of the cervix can be assessed using the Bishop score and ultrasonographically determined length of the cervical canal and internal os. Consistency is one of the cervical properties that change during the course of the maturation process. Until recently, cervical consistency has been assessed only manually, but in 2007, the first report on elastographic imaging of the cervix during pregnancy has been published. Elastography presents the ability of a tissue to deform under pressure. The softer the tissue, the easier it changes its shape. Different methods of elastography are used - static, when tissue displacement in response to manual compression or physiological movements of vessels is measured, or dynamic, when the speed of shear wave propagation is determined. Irrespective of the method, elastography provides information on the internal os stiffness; this parameter, impossible for manual assessment, was shown to correlate with pregnancy outcome and is a strong predictor of preterm delivery or successful labor induction. Although elastography seems to be a highly promising diagnostic option, still no consensus has been reached regarding an optimal method for uterine cervix assessment, and virtually all previous studies of various elastographic methods produced highly satisfactory results. Future studies need to identify the most promising and objective elastographic method which may serve as a novel tool for pregnancy management, preventing adverse events, such as preterm delivery and unsuccessful labor induction.

Keywords: consistency, elastography, labor induction, preterm delivery, uterine cervix

\section{Cervix properties}

Uterine cervix is a part of the uterus responsible for maintaining pregnancy till term. As long as the cervix remains long and firm and its internal orifice (os) is closed, it can withstand enlargement of the uterine contents and the resultant growing pressure. Mechanical properties of the cervix change throughout pregnancy; the cervix ripens prior to delivery, then effaces and dilates with contractions of the uterus. Improper ripening of the cervix may result in preterm delivery when it starts too early, or in post-term pregnancy and cervical dystocia when it progresses too slow. ${ }^{1-3}$

Mechanical properties of the cervix change throughout pregnancy. An increase in water content and remodeling of collagen result in softening of cervical tissue prior to delivery. This process is referred to as cervical ripening, and unless it is complete, the cervix will neither shorten nor dilate in response to uterine contractions; this phenomenon is known as the cervical dystocia. Cervical ripening can be accelerated by administration of prostaglandins. These agents not only induce uterine 
contractions but also alter the structure of the cervix, preparing it for labor. ${ }^{1-3}$

Whenever cervical ripening proceeds too fast, it may result in cervical incompetence. Despite low uterine tone and lack of contractions, the cervix starts to shorten, its internal os opens and the fetus may be expelled with nearly no complaints from the pregnant woman. This makes the studies assessing cervical length screening at 18-22 weeks of gestation (and supplementing progesterone in all patients diagnosed with short cervix to prevent preterm delivery) to be of very high value. ${ }^{4}$ Although the measurement of the uterine cervix can be also considered in the prediction of preterm delivery in women without cervical incompetence, to this date, no treatment has been shown to effectively prolong pregnancy in this group.

Accurate cervical assessment may be challenging in the case of threatened preterm labor or prolonged pregnancy, as available diagnostic tools are far from being perfect. Measurement of cervical length and assessment of the internal os were shown to be highly useful diagnostic options. Measurement of the cervix in pregnant women has been first described by Zemyln in 1981, and since then, clinical implications of short cervix have been a subject of thousands of published studies. ${ }^{5}$ However, it should be remembered that cervical length and internal os diameter are only two among many cervical factors that may predict labor onset.

Cervical stiffness seems to be an equally important predictor of labor onset as the two parameters mentioned above. Assessment of cervical consistency has been first described by Bishop, and the scale proposed by this author to estimate the readiness for delivery is still in use nowadays. ${ }^{6}$ Although an unquestioned advantage of this subjective scale based solely on manual examination is its simplicity, modern obstetricians need new, more objective and accurate methods for cervical assessment.

\section{Elastography - physical properties}

Elasticity of a tissue can be measured directly as a distance of its displacement after applying compression - softer tissue moves easier than the hard one (Figure 1). When compressed, the tissue becomes thinner and wider. Deformation of the tissue may be described by Young's modulus or shear modulus. Young's modulus describes how difficult it is to deform tissue by compression. Shear modulus indicates how difficult transverse wave propagates in the tissue. ${ }^{7}$

The degree to which the tissue deforms when compression is applied depends not only on its stiffness in the region of interest but also on the characteristics of surrounding tissues,

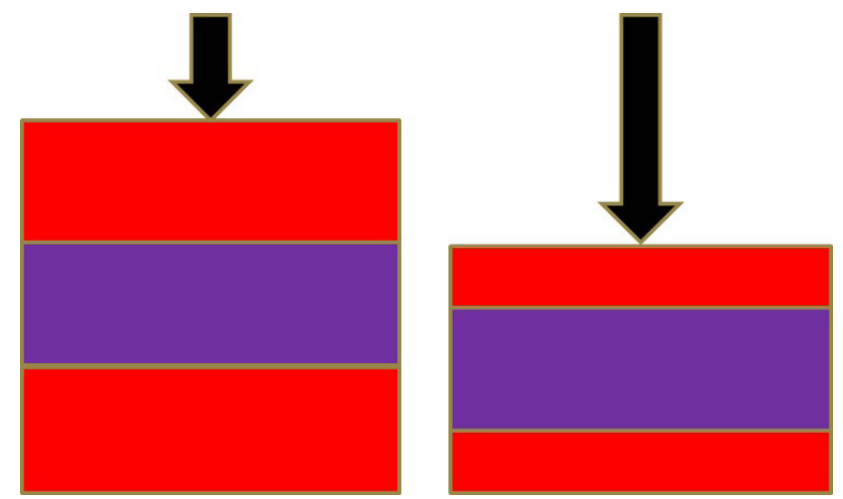

Figure I Physical description of static elastography.

Note: Pressure applied perpendicularly (black arrows) compresses soft material (red) more than hard material (purple).

the shape and size of the analyzed organ, homogeneity of the anatomical area and many other factors. Therefore, direct application of Young's modulus may be highly challenging in the case of biological tissues due to anisotropy, viscosity and nonlinear characteristics of the latter. ${ }^{7}$ Nevertheless, analysis of tissue deformity performed quite well in distinguishing tumors from normal tissues in some organs, namely the breasts and thyroid. ${ }^{8,9}$ Unfortunately, the same does not apply to the assessment of whole-organ stiffness, as no tissue can be used as a reference point in such cases.

\section{Elastography - methods}

Elastography is a new ultrasound-based method used to noninvasively assess mechanical properties of a tissue. The principles of elastography have been recently described by Shiina et al. ${ }^{7}$ This author distinguished between four different types of tissue assessment, depending on the method used to generate a tissue-deforming impulse (manual compression, acoustic radiation force or mechanic external vibration) and the measure of physical response within the tissue (strain ratio vs speed of displacement propagation). ${ }^{7}$ All these techniques, except for the mechanic external vibration, have been used to assess the uterine cervix in previous studies.

Tissue-deforming impulse may be generated in three mechanisms. The first one, used in static elastography, is a movement of the probe (manual compression applied by the operator), cardiovascular movement of the tissue caused by the blood flow in the vessels, or respiration. The waves produced this way propagate in the same direction as the tissue is displaced. The second mode of generating impulse is generating the tissue movement by applying acoustic radiation force. In this method, focused ultrasound beams are sent to the region of interest, and they displace the tissue by shear wave propagating orthogonally to the direction of 
tissue displacement. The speed of the generated shear wave propagation away from the point where the impulse was directed may be assessed in two-dimensional (2D) images, and Young's modulus can be calculated. The third mechanism, external vibration creating a tissue movement, is used in magnetic resonance elastography, and so far, has not been applied in obstetrics.?

Strain or static elastography is based on the measurement of tissue displacement under compression. Compression can be obtained with a manual force applied via an ultrasound transvaginal probe or created by physiological cardiovascular processes and breath. ${ }^{7}$ Neither waves nor vibrations are used to cause tissue deformation during static elastography. While manual compression is highly subjective, analysis of tissue deformity during physiological processes produces less operator-dependent results. Furthermore, neither method of compression is objective nor standardized.

No standards for creating compression with a transvaginal probe have been developed thus far. Some software packages delivered with ultrasonographic equipment specify pressure indicators, but these are only relative values reflecting deformity of the tissue and therefore, depending on the consistency of the latter. Although some procedures for pressure standardization have been proposed, they are also not adjusted for tissue consistency. For example, according to Molina et al, manual force applied with the probe should cause a 1-cm displacement of the cervix. However, the softer the cervix, the less pressure is needed to displace it by $1 \mathrm{~cm}$, which may influence the result of the measurement. ${ }^{10}$ In turn, Fruscalzo et al recommends to press with the probe until no further compression of the anterior lip is possible and the posterior lip starts to move. ${ }^{11}$ Also in this case, manual force applied onto the probe depends on the cervical stiffness: the softer the cervix, the less pressure is required to compress it to that point. Owing to the limitations specified above, still no consensus has been reached with regard to the probe pressure standardization during elastography.

The result of elastographic measurement also depends on the phase of compression (application of pressure vs relaxation) and the size of the region of interest (ROI). According to Fruscalzo et al, the smaller the ROI, the more reliable the measurement. Furthermore, higher strain ratios are documented during the compression phase than during relaxation. ${ }^{12}$ The definition of ROI differs depending on an investigator. Some authors, for example, Hwang et al, consider whole cervix as the ROI; ${ }^{13}$ others define ROI as a round area, $5 \mathrm{~mm}$ in diameter, located at the internal os or at any other place in a specified distance from the latter. ${ }^{10,12,14}$
The results of elastographic measurements, even taken with the same equipment, will not be comparable unless a widely accepted standardized examination protocol is developed.

The compression of the probe and displacement of the tissue cause a change in the time of the return of the ultrasound beam to the probe. When the tissue is soft, it is compressed more with the same pressure, and becomes closer to the probe, than the hard part of the organ. It means that the ultrasound signal is coming back from the soft part faster than from the hard part after applying compression. The correlation of time of the beam return before and after compression is calculated and presented on the screen in a scale of colors - shades of gray or any other scale using colors of the rainbow. ${ }^{7}$ Examples of acquired images are presented in Figures 2 and 3.

Strain ratio reflects the difference in the displacement of ROI and the displacement of the reference region. When elastographic measurement involves the area of a suspected tumor, consistency of surrounding normal tissue can be considered as the reference value. Under such circumstances, the strain ratio reflects how many times the tumor is harder or softer than the normal tissue around it. Unfortunately, no reference region can be defined during elastographic examination of the cervix in pregnant women; the aim of the elastography is to determine whether the cervix is softer than before. This issue represents another drawback of static cervical elastography.

A reference device with a known stiffness placed on top of the transvaginal probe is supposed to help standardize the measurements. Regardless of the pressure applied with

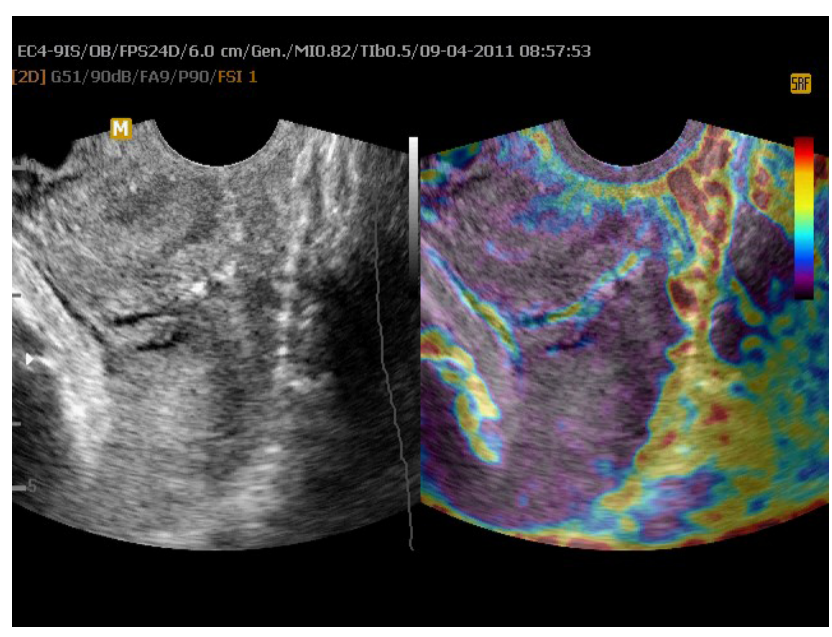

Figure 2 Uterine cervix in static elastography.

Notes: Left part of the image presents a B-mode image of the cervix; on the right side, elastogram with hard tissue presented as purple and soft as red is applied on the two-dimensional image. 


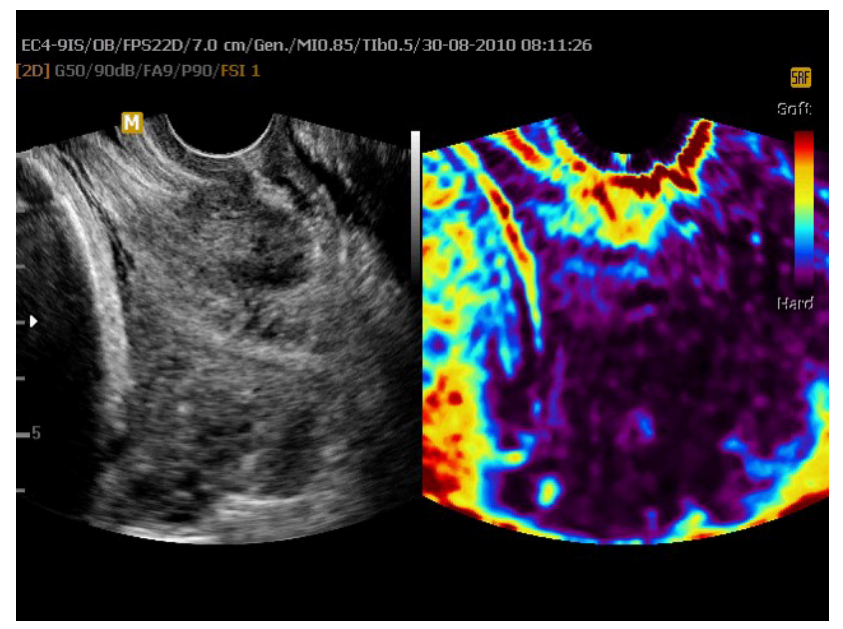

Figure 3 Uterine cervix in static elastography.

Notes: Left part of the image presents a B-mode image of the cervix; on the right side, elastogram is presented.

the probe, the cervical strain ratio calculated against the reference region of the device will be more reliable than the value obtained when the deformability of the ROI and another part of the cervix are compared. The reference cap was first described in 2013, but it did not receive an enthusiastic feedback due to the necessity of mounting an additional device on top of the probe. ${ }^{15}$ A reference cap integrated with the probe would with no doubt facilitate the elastographic measurement; unfortunately, it would also limit application of the probe to elastography only. Consequently, the probe with the integrated device would need to be replaced by a conventional one to determine other ultrasonographic parameters, for example, cervical length. This would negatively affect both patient's and examiner's comfort.

The aim of shear wave elastography (dynamic elastography) was to determine the propagation speed of a shear wave induced by an ultrasound probe. Shear wave is a transverse wave deforming tissue as far from the probe as it penetrates. The depth of penetration depends on the intensity and duration of the wave, as well as on the tissue stiffness. Deformation of the tissue progresses with the shear wave, and both the absolute propagation speed and a relative decrease in this parameter with the distance from the probe can be measured by ultrasound. ${ }^{7}$

Since generation of the shear wave is not influenced by the operator, this type of elastography produces more objective results. Although no safety data regarding the use of shear wave in pregnancy and its influence on the fetus have been published to date, the fact that the Aixplorer ultrasound system has been approved for in vivo applications by both the US Food and Drug Administration and the Europe Union's Certificate of Conformity likely reflects the lack of safety concerns. According to the literature, thermal and mechanical indices of shear wave elastography do not exceed the respective safety limits and are only slightly higher than analogous parameters recorded during conventional B-mode imaging. ${ }^{16}$

\section{Assessment of elastography}

Once the elastographic image is obtained, it needs to be assessed. Depending on the elastographic software vendor, various calculation models are proposed.

Shortly after implementation of elastography to clinical practice, Yamaguchi et al proposed a color scale to describe elastographic characteristics of the cervix in pregnancy: hard, soft and medium-hard tissues were highlighted in blue, red and green, respectively. ${ }^{17}$ In 2010, Preis et al proposed another scale referred to as elastography index, in which points were assigned to each color present on elastographic images (from 0 for the hardest purple tissue to 4 for the softest red regions). Every part of the cervix was assessed separately. The number assigned to the part (eg, internal os) was the number corresponding to the softest region of the selected part. ${ }^{18}$ Muscatello et al proposed a slightly modified version of this scale, but still using the same idea, that is, assigning numbers to colors. ${ }^{19}$ An unquestioned advantage of the above-mentioned scoring systems is their simplicity and the fact that they are not time consuming; therefore, the result can be obtained at the time of examination. However, the question arises how to distinguish which part of the cervix belongs to the internal os, external os, anterior lip and so on? This question was addressed by Swiatkowska-Freund et al, according to whom both repeatability and reproducibility of the elastography index are very high, especially after a short training. ${ }^{20}$

Hwang et al used computer-based pixel analysis of elastographic images to determine mean elastographic index and to identify the hardest areas of the cervix. ${ }^{13}$ Sabiani et al proposed an index obtained by dividing the strain for the anterior lip by the sum of strains for the anterior and posterior lip. ${ }^{21}$ In more recently developed methods, strain ratio is calculated automatically by comparing ROI with the reference region defined by the operator or with the reference cap of known stiffness. ${ }^{22,23}$ However, this approach is still not objective as the result depends on the size and location of the regions defined by the operator. As mentioned previously, identification of the reference region for elastographic examination is always a challenge. None of the cervical segments retain the same consistency throughout the whole pregnancy. Consequently, no reliable results can be obtained 
Table I Studies on feasibility of elastography in presenting changes in uterine cervix during pregnancy and reproducibility of this method

\begin{tabular}{|c|c|c|c|c|c|}
\hline Author (year) & Equipment & Mode & $\begin{array}{l}\text { Tissue-deforming } \\
\text { impulse }\end{array}$ & $\begin{array}{l}\text { Method of } \\
\text { assessment }\end{array}$ & Application \\
\hline $\begin{array}{l}\text { Yamaguchi } \\
\text { et al }{ }^{17}(2007)\end{array}$ & Hitachi EUB-8500 & Static & Probe movement & Color assessment & $\begin{array}{l}\text { Visualization of the } \\
\text { cervix during pregnancy }\end{array}$ \\
\hline $\begin{array}{l}\text { Fruscalzo et } a^{26} \\
(2012)\end{array}$ & Toshiba Aplio XG & Static & Probe movement & Strain ratio & $\begin{array}{l}\text { Reliability, cervical } \\
\text { changes during pregnancy }\end{array}$ \\
\hline Molina et $\mathrm{al}^{10}(20 \mid 2)$ & Toshiba Aplio MX & Static & Probe movement & Strain ratio & Reproducibility \\
\hline Hee et al ${ }^{15}(2013)$ & $\begin{array}{l}\text { GE Voluson E8 } \\
\text { Expert }\end{array}$ & Static & Probe movement & $\begin{array}{l}\text { Strain ratio compared } \\
\text { to reference cap }\end{array}$ & $\begin{array}{l}\text { Cervical changes during } \\
\text { pregnancy }\end{array}$ \\
\hline $\begin{array}{l}\text { Hernandez-Andrade } \\
\text { et } \mathrm{a}^{25}(2013)\end{array}$ & $\begin{array}{l}\text { Hitachi HI Vision } \\
9000\end{array}$ & Static & Probe movement & Color assessment & $\begin{array}{l}\text { Cervical changes during } \\
\text { pregnancy }\end{array}$ \\
\hline $\begin{array}{l}\text { Fruscalzo et al" } \\
(2014)\end{array}$ & Toshiba Aplio XG & Static & Probe movement & Strain ratio & $\begin{array}{l}\text { Reproducibility, cervical } \\
\text { changes during pregnancy }\end{array}$ \\
\hline Hee et a $\left.\right|^{22}(2014)$ & GE Voluson E8 & Static & Probe movement & $\begin{array}{l}\text { Strain ratio compared } \\
\text { to reference cap }\end{array}$ & Reproducibility \\
\hline $\begin{array}{l}\text { Hernandez-Andrade } \\
\text { et } \mathrm{a}^{27}(2014)\end{array}$ & SuperSonic Imagine & Dynamic & Shear wave & $\begin{array}{l}\text { Measurement of } \\
\text { speed of propagation }\end{array}$ & $\begin{array}{l}\text { Cervical changes during } \\
\text { pregnancy }\end{array}$ \\
\hline $\begin{array}{l}\text { Swiatkowska- } \\
\text { Freund et al }{ }^{20}(2014)\end{array}$ & $\begin{array}{l}\text { Medison Accuvix } \\
\text { VI0 }\end{array}$ & Static & $\begin{array}{l}\text { Cardiovascular } \\
\text { movement }\end{array}$ & Color assessment & $\begin{array}{l}\text { Reproducibility of color } \\
\text { assessment }\end{array}$ \\
\hline $\begin{array}{l}\text { Fruscalzo et al } \\
(2015)\end{array}$ & Toshiba Aplio XG & Static & Probe movement & Strain ratio & $\begin{array}{l}\text { Influence of settings on } \\
\text { strain calculation }\end{array}$ \\
\hline Muller et al ${ }^{16}(2015)$ & $\begin{array}{l}\text { Aixplorer } \\
\text { SuperSonic Imagine }\end{array}$ & Dynamic & Shear wave & $\begin{array}{l}\text { Measurement of } \\
\text { speed of propagation }\end{array}$ & Reproducibility \\
\hline Peralta et al ${ }^{32}(2015)$ & SuperSonic Imagine & Dynamic & Shear wave & $\begin{array}{l}\text { Measurement of } \\
\text { speed of propagation }\end{array}$ & $\begin{array}{l}\text { Cervical changes during } \\
\text { pregnancy }\end{array}$ \\
\hline
\end{tabular}

when two different parts of the cervix, both expected to get softer with gestational age, are compared.

Furthermore, an anatomical plane which provides the most reliable estimates of cervical stiffness is still a matter of discussion. The authors of early reports took elastographic measurements in a mid-sagittal plane, which is used for the measurement of the cervical canal. ${ }^{10,18,24}$ However, in 2013 Hernandez-Andrade et al suggested that elastographic measurements of the internal os and cervical canal may be more reliable when taken in a cross-sectional plane rather than in a sagittal plane. ${ }^{25}$

Although they are far from being perfect from a theoretical point of view, evidence from a few published studies suggests that reproducibility of elastographic estimates obtained with the above-mentioned scoring methods is quite satisfactory. ${ }^{23,26,27}$ This implies that irrespective of the type of equipment, elastographic method, measurement and scoring strategy, elastography produces reliable and comparable results (Table 1$)$.

\section{Ripening of the cervix}

Published evidence suggests that physiological changes in cervical stiffness can be documented on elastographic images. Internal os cannot be examined manually during pregnancy. Therefore, whenever the cervix is described as soft on the basis of manual examination, this refers to its vaginal portion, usually to the external os. Sparse evidence suggests that cervical incompetence is likely a consequence of tissue softening at the area of the internal os.

Thomas, in 2006, presented first elastographic images of the uterine cervix, but it was obtained in non-pregnant women. ${ }^{28}$ Application of elastography in obstetrics was first reported in 2007; Yamaguchi et al described the possibility of cervix imaging with the use of this method during pregnancy. Cervical stiffness assessed after manual compression was expressed using the previously mentioned color scale. Since the results obtained with manual compression are to a large extent operator dependent, this approach was likely as subjective as the Bishop score. ${ }^{17}$

Hernandez-Andrade et al compared shear wave speed (SWS) in the region of the internal and external os, and Fruscalzo et al analyzed these two parts of the cervix by strain elastography. Irrespective of the elastographic method used, internal os seemed to be denser than surrounding tissues, thus supporting a popular hypothesis that this anatomical region is crucial for maintaining pregnancy. ${ }^{11,14}$

Carlson et al used an ex vivo model to demonstrate the differences in shear wave propagation speed in ripened 
and non-ripened human cervix. ${ }^{29}$ Huang et al presented, in 2016, a paper on shear wave propagation in rhesus macaques' uterine cervices examined ex vivo before and after misoprostol administration. He showed that opposite to human cervix, macaque cervix does not change its stiffness after ripening. ${ }^{30}$ In 2015, Peralta et al documented, for the first time, shear wave changes associated with cervical ripening in vivo using an animal model. The latter author supported these findings with histological analysis and microstructure of the cervical tissue. ${ }^{31}$ He also presented results of assessment of the human cervix during pregnancy and showed that dynamic elastography measurements have correlation with gestational age and time remaining for delivery. ${ }^{32}$ The results reported by both the authors mentioned above suggest that cervical ripening may be associated with changes in shear wave propagation, but this hypothesis still needs to be confirmed during in vivo studies of pregnant women.

\section{Preterm delivery}

Preterm delivery is the most common cause of neonatal mortality and morbidity. Unfortunately, still there is no reliable method to distinguish between pregnant women with increased risk of preterm labor who require particularly thorough monitoring, and those who are likely to deliver at term despite reported uterine contractions and shortening of the cervix. As a result, we offer unnecessary treatment to many women who would otherwise deliver at term despite the presence of risk factors for preterm labor. The proportion of pregnant women who have been hospitalized due to threatened preterm labor and eventually delivered at term is estimated to be more than $50 \% .^{33}$

Elastographic assessment of the cervix seems to add some information to that obtained with other conventional methods used to assess the risk of preterm delivery. Bishop score did not prove to be a reliable measure of pregnancyrelated changes in the cervix, even in women with high risk of preterm labor. An increase in the Bishop score suggests that the labor has already started and typically cannot be stopped. While ultrasonographic evidence of cervical shortening and opening of the internal os is much better predictor of preterm labor, it is still far from being perfect.

Although not fully objective, elastography seems to provide a useful additional information on cervical stiffness. In our opinion, elastography represents a promising tool for the assessment of preterm labor risk; since aside from providing an objective information about cervical consistency, it is also suitable for the evaluation of the internal os, a region that cannot be examined by palpation.
Stiffness of the internal os can be determined by means of strain elastography, using a color scale (eg, that proposed by Preis et $\mathrm{al}^{18}$ ) or based on a strain ratio between the reference region and ROI. ${ }^{7}$ The first method has already been used to predict preterm delivery in a group of women who reported uterine contractions. The study demonstrated an association between the elasticity of the internal os and the risk of preterm labor; women whose internal os was classified as soft (yellow and red) were more likely to deliver preterm, and gave birth in a shorter time after the elastographic examination. ${ }^{33}$

Wozniak et al examined a group of women at low risk of preterm labor and also found an association between lesser stiffness of the internal os (red or yellow color) at $18-22$ weeks of gestation and the risk of preterm delivery (81.1\% for women with soft internal os vs $1.7 \%$ for women with firm internal os). ${ }^{34}$ The same author used elastography to predict the risk of preterm labor in a group of women with cervical shortening at 18-22 weeks of gestation; elastographic evidence of lesser stiffness of the internal os (red or yellow color) provided relatively high sensitivity, specificity, negative and positive predictive values in prediction of preterm labor. ${ }^{35}$ Similar results were reported by HernandezAndrade et al for a group of women at low risk of preterm birth. This author analyzed values of strain ratio for quartiles of each studied region: endocervical region and whole cervix, determined in various planes. The presence of soft tissue in the area of the internal os turned out to be associated with increased risk of preterm delivery. However, no significant associations were found between the risk of preterm labor and elastographic characteristics of the whole cervix and external os, which is consistent with the findings reported by Swiatkowska-Freund et al and Wozniak et al. ${ }^{33-36}$

Application of shear wave elastography in prediction of preterm labor was first reported in $2015 .{ }^{16}$ Cervical SWS was shown to correlate with gestational age, presence of preterm uterine contractions and, most importantly, with the risk of preterm delivery.

All the studies mentioned above are collected and shortly described in Table 2.

Identification of patients who are truly at risk of preterm labor is one of the challenges of modern obstetrics. Whereas the vast majority of fetal defects can be easily detected or even treated in utero, the estimates of preterm labor risk are accurate in no more than $50 \%$. Hopefully, further extensive research on elastographic assessment of the uterine cervix, especially internal os stiffness, will eventually result in implementation of this method in a routine clinical practice. Then, we will be able to avoid an unnecessary intervention 
Table 2 Studies on elastography of uterine cervix as a predictor of preterm delivery

\begin{tabular}{|c|c|c|c|c|}
\hline Author (year) & Equipment & Mode & Tissue-deforming impulse & Method of assessment \\
\hline Hernandez-Andrade et al ${ }^{14}(2014)$ & Hitachi HI Vision 900 & Static & Probe movement & Strain ratio \\
\hline Swiatkowska-Freund et al ${ }^{33}(2014)$ & Medison Accuvix VIO & Static & Cardiovascular movement & Color assessment \\
\hline Wozniak et $\mathrm{al}^{34}(2014)$ & Medison Accuvix V20 & Static & Cardiovascular movement & Color assessment \\
\hline Hernandez-Andrade et $\mathrm{al}^{36}(2015)$ & Hitachi HI Vision 9000 & Static & Probe movement & Strain ratio \\
\hline Muller et al ${ }^{16}(2015)$ & Aixplorer SuperSonic Imagine & Dynamic & Shear wave & Measurement of speed of propagation \\
\hline Sabiani et $\mathrm{al}^{21}(2015)$ & Hitachi HI Vision EUB-8500 & Static & Probe movement & Color assessment \\
\hline Wozniak et al ${ }^{34}(2015)$ & Medison Accuvix V20 & Static & Cardiovascular movement & Color assessment \\
\hline
\end{tabular}

in women in whom the risk of preterm labor is low despite the presence of uterine contractions and short uterine cervix. This would not only improve comfort of pregnant women but also reduce unnecessary economic burden associated with pregnancy management. Consequently, another beneficiary of progress in elastographic assessment of the cervix is insurance companies, at least as long as it will result in lesser costs of management in patients at increased risk of preterm delivery.

\section{Cervical incompetence}

One cause of prematurity is cervical incompetence. It is defined as a cervical failure to maintain pregnancy till term, when the cervix shortens and dilates prematurely without uterine contractions, usually in the second trimester. The only available treatment is mechanical closure of the cervix by means of cerclage or pessary, and administration of progesterone. However, this treatment is usually ineffective when the cervix has been already shortened and dilated. The first report documenting application of elastography in prediction of cervical incompetence in non-pregnant cervix was published in $2015 .{ }^{37}$ Although still not verified in a clinical setting, prophylactic administration of progesterone to women presenting with soft internal os before becoming pregnant seems to be a promising option in the prevention of cervical incompetence.

\section{Labor induction}

Induction of labor with oxytocin infusion can be successful whenever the cervix is ripened and ready for delivery. Each attempt of labor induction is always preceded by evaluation of the cervix to assess the risk of failure and to identify women who require preinduction with prostaglandins or Foley catheter instead of the oxytocin infusion. Inaccurate cervical assessment will usually result in a failure of labor induction and cesarean section. Therefore, the choice of an appropriate method for induction or preinduction of labor is a key to reduce cesarean section rate, especially in postterm pregnancies.
The use of the Bishop score as a measure of cervical ripening produces much better results in qualification for labor induction than in the assessment of preterm labor risk. Nevertheless, this method to assess cervical consistency is still highly subjective and should be supported by more reliable tools. Elastographic assessment of the internal os seems to be a highly promising method in this context.

The first report documenting an association between internal os stiffness and the outcome of labor induction with oxytocin was published in $2011 .{ }^{24}$ The authors of this study found no correlation between elastographic properties of other parts of the cervix and labor induction success. Although the study was based on the earliest, relatively subjective elastographic methods (assessment of strain in cervical tissues deformed due to physiological cardiovascular processes, expressed on a color scale), it produced statistically significant results that have been further confirmed by other authors: the softer the internal os, the higher the success rate of labor induction. However, none of the further studies analyzed an association between elastographic findings and the success of labor induction with oxytocin. Importantly, infusion of this hormone induces uterine contractions but, contrary to prostaglandin administration and insertion of Foley catheter, does not influence mechanical properties of the cervix. Any alteration of the mechanical properties of the cervix will be reflected by a change in its consistency on elastographic images. Furthermore, the more ripened the cervix, the more greater its reactivity after administration of oxytocin. Therefore, in our opinion, correlation between elastographic properties of the cervix and the outcome of labor induction with oxytocin should be the strongest in cases in which no attempt to induce cervical ripening has been made. However, it cannot be excluded that the softer the internal os, the easier is the cervical ripening after administration of prostaglandins or the stronger and the faster is the cervical response to insertion of Foley catheter.

In 2014, Muscatello et al published the results of a study analyzing the link between elastographic findings and labor induction with prostaglandins. According to this 
author, elastographic evidence of soft internal os (more red, yellow and green) was associated with greater likelihood of vaginal delivery, whereas the presence of hard internal os was related to higher risk of cesarean section. ${ }^{19}$ According to Fruscalzo et al, the odds of successful induction of labor with prostaglandins are greater whenever anterior lip of the cervix is softer than the posterior lip. ${ }^{38}$ Altogether, this evidence suggests that the likelihood of successful labor induction after administration of prostaglandins is greater in patients with less stiff internal os and anterior lip.

Another method for labor induction is insertion of Foley catheter beyond the internal os of the cervix. Pressure of the catheter onto the internal os stimulates uterine contractions and should induce labor in patients with a ripened cervix. Wozniak et al used strain elastography to determine cervical stiffness prior to the induction of labor with Foley catheter. They found a link between elastographic parameters of the cervix, time elapsed between catheter insertion and vaginal delivery, and success rate of labor induction. Specifically, women who presented with softer internal os and cervical canal on strain elastography delivered sooner and had lower risk of cesarean section due to prolonged labor. ${ }^{39}$

In 2014, Pereira et al reported lack of correlation between the value of elastographic index (internal-to-external os stiffness ratio) and the success rate of labor induction. However, they used different methods for labor induction and analyzed patients with different gestational age; therefore, these findings are hardly comparable with the results of previous studies dealing with the problem in question. Nevertheless, this is only one of a few articles demonstrating lack of correlation between the elastographically determined stiffness of the internal os and pregnancy outcome. ${ }^{40}$

In 2016, Londero et al published the results of a metaanalysis examining the accuracy of various methods for cervical assessment in prediction of successful labor induction and vaginal delivery. In this study, cervical elastography and measurement of cervical length turned out to be equally reliable predictors of successful labor induction and vaginal delivery, more accurate than the Bishop score. ${ }^{41}$

To the best of our knowledge, none of the published studies analyzed the value of shear wave elastography in prediction of successful labor induction. Carlson et al, in 2015 , presented a paper describing differences in cervical stiffness assessed by shear wave before and after prostaglandins administration for cervical ripening. Analyzed group was very small and authors did not refer to the success of labor induction in the subgroup "not in labor." 42

All the studies described in this capture are presented in Table 3.

\section{Do we really need numbers?}

Considering the evidence from all the studies mentioned above and taking into account the reality of obstetrical practice, we should ask what are our true expectations regarding elastography?

We found this method to be highly promising, as it allows one to determine the stiffness of otherwise inaccessible internal os. The results of all the studies reviewed above imply that regardless of the elastographic method used to assess it, the consistency of the internal os predicts the risk for preterm

Table 3 Studies on elastography of the uterine cervix as a predictor of result of labor induction and progress of labor

\begin{tabular}{|c|c|c|c|c|c|}
\hline Author (year) & Equipment & Mode & $\begin{array}{l}\text { Tissue-deforming } \\
\text { impulse }\end{array}$ & $\begin{array}{l}\text { Method of } \\
\text { assessment }\end{array}$ & $\begin{array}{l}\text { Method of labor } \\
\text { induction }\end{array}$ \\
\hline Preis et $\mathrm{al}^{18}(2010)$ & Medison Accuvix VIO & Static & Cardiovascular movement & Color assessment & Oxytocin \\
\hline $\begin{array}{l}\text { Swiatkowska-Freund } \\
\text { and Preis }{ }^{24}(20 \mathrm{II})\end{array}$ & Medison Accuvix VIO & Static & Cardiovascular movements & Color assessment & Oxytocin \\
\hline Hwang et $\mathrm{al}^{13}(20 \mathrm{l} 3)$ & $\begin{array}{l}\text { Samsung Medison } \\
\text { Accuvix XG }\end{array}$ & Static & Cardiovascular movement & $\begin{array}{l}\text { Image optical analyzer } \\
\text { of colors }\end{array}$ & Oxytocin \\
\hline Hee et $\mathrm{al}^{22}(2014)$ & GE Voluson E8 & Static & Probe movement & $\begin{array}{l}\text { Strain ratio compared } \\
\text { to reference cap }\end{array}$ & Prostaglandins \\
\hline $\begin{array}{l}\text { Muscatello et al }{ }^{19} \\
(2014)\end{array}$ & $\begin{array}{l}\text { Samsung Medison } \\
\text { Accuvix VIO }\end{array}$ & Static & Cardiovascular movement & Color assessment & Prostaglandins \\
\hline Pereira et $\mathrm{al}^{40}(20 \mid 4)$ & $\begin{array}{l}\text { Samsung Medison } \\
\text { Accuvix XG }\end{array}$ & Static & Cardiovascular movement & $\begin{array}{l}\text { Samsung-Medison } \\
\text { "stiffmetool" analysis } \\
\text { of color }\end{array}$ & Different methods \\
\hline $\begin{array}{l}\text { Carlson et } \mathrm{al}^{42} \\
(2015)\end{array}$ & $\begin{array}{l}\text { Siemens Acuson } \\
\text { S2000 }\end{array}$ & Dynamic & Shear wave & $\begin{array}{l}\text { Measurement of } \\
\text { speed of propagation }\end{array}$ & Prostaglandins \\
\hline Fruscalzo et $\mathrm{al}^{38}$ (2015) & Toshiba Aplio XG & Static & Probe movement & Strain ratio & Prostaglandins \\
\hline Wozniak et $\mathrm{al}^{39}$ (2015) & Medison Accuvix V20 & Static & Cardiovascular movement & Color assessment & Foley catheter \\
\hline Londero et $\mathrm{al}^{4 \mid}(2016)$ & Meta-analysis & & & & \\
\hline
\end{tabular}


delivery and the likelihood of labor induction success. Since this part of the cervix is inaccessible for manual evaluation, its elastographic assessment adds considerably to the results of vaginal examination and measurement of cervical canal and internal os.

Available evidence confirms unequivocally that irrespective of its method, elastography provides useful data on pregnancy-related changes in the cervix and should be considered in planning of further pregnancy management. Assuming that the assessment of the internal os stiffness using a color scale is equally valuable as the measurement of the strain ratio or SWS, one may ask if we really need to use these more complicated and time-consuming modalities? Perhaps, it is enough to conclude that the internal os is soft on the basis of its color on elastographic images? While many of us may prefer more accurate information, for example, "Strain ratio is 0.7 " or "SWS is $1.5 \mathrm{~m} / \mathrm{s}$ " and would like to adhere to some clearly defined cut-off values, maybe others may benefit equally from the information that the internal os is soft whenever it is red or yellow.

One potential weakness of the hereby presented evidence is heterogeneity of equipment used by various authors. Each vendor of ultrasonographic equipment uses his own modifications of elastography, which limits the possibility of comparative analyses. Therefore, we need to decide which of the available elastographic methods is the most promising, the easiest and the most reliable. Then all the companies should be motivated to improve this technique rather than developing the new ones.

\section{Disclosure}

The authors report no conflicts of interest in this work.

\section{References}

1. Myers KM, Paskaleva AP, House M, Socrate S. Mechanical and biochemical properties of human cervical tissue. Acta Biomater. 2008; 4(1):104-116.

2. House M, Kaplan DL, Socrate S. Relationships between mechanical properties and extracellular matrix constituents of the cervical stroma during pregnancy. Semin Perinatol. 2009;33(5):300-307.

3. Myers KM, Feltovich H, Mazza E, et al. The mechanical role of the cervix in pregnancy. $J$ Biomech. 2015;48(9):1511-1523.

4. Menon R, Torloni MR, Voltolini C, et al. Biomarkers of spontaneous preterm birth: an overview of the literature in the last four decades. Reprod Sci. 2011;18(11):1046-1070.

5. Zemlyn S. The length of the uterine cervix and its significance. J Clin Ultrasound. 1981;9(6):267-269.

6. Bishop EH. Pelvic scoring for elective induction. Obstet Gynecol. 1964;24:266-268.

7. Shiina T, Nightingale KR, Palmeri ML, et al. WFUMB guidelines and recommendations for clinical use of ultrasound elastography: Part 1: basic principles and terminology. Ultrasound Med Biol. 2015;41(5): $1126-1147$.
8. Thomas A, Degenhardt F, Farrokh A, Wojcinski S, Slowinski T, Fischer T. Significant differentiation of focal breast lesions: calculation of strain ratio in breast sonoelastography. Acad Radiol. 2010;17(5): $558-563$.

9. Dighe M, Kim J, Luo S, Kim Y. Utility of the ultrasound elastographic systolic thyroid stiffness index in reducing fine-needle aspirations. J Ultrasound Med. 2010;29(4):565-574.

10. Molina FS, Gómez LF, Florido J, Padilla MC, Nicolaides KH. Quantification of cervical elastography: a reproducibility study. Ultrasound Obstet Gynecol. 2012;39(6):685-689.

11. Fruscalzo A, Londero AP, Fröhlich C, Möllmann U, Schmitz R. Quantitative elastography for cervical stiffness assessment during pregnancy. Biomed Res Int. 2014;2014:826535.

12. Fruscalzo A, Londero AP, Schmitz R. Quantitative cervical elastography during pregnancy: influence of setting features on strain calculation. J Med Ultrason (2001). 2015;42(3):387-394.

13. Hwang HS, Sohn IS, Kwon HS. Imaging analysis of cervical elastography for prediction of successful induction of labor at term. J Ultrasound Med. 2013;32(6):937-946.

14. Hernandez-Andrade E, Romero R, Korzeniewski SJ, et al. Cervical strain determined by ultrasound elastography and its association with spontaneous preterm delivery. J Perinat Med. 2014;42(2):159-169.

15. Hee L, Sandager P, Petersen O, Uldbjerg N. Quantitative sonoelastography of the uterine cervix by interposition of a synthetic reference material. Acta Obstet Gynecol Scand. 2013;92(11):1244-1249.

16. Muller M, Ait-Belkacem D, Hessabi M, et al. Assessment of the cervix in pregnant women using shear wave elastography: a feasibility study. Ultrasound Med Biol. 2015;41(11):2789-2797.

17. Yamaguchi S, Kamei Y, Kozuma S, Taketani Y. Tissue elastography imaging of the uterine cervix during pregnancy. J Med Ultrason (2001). 2007;34(4):209-210.

18. Preis K, Swiatkowska-Freund M, Pankrac Z. [Elastography in the examination of the uterine cervix before labor induction]. Ginekol Pol. 2010;81(10):757-761. Polish [with English abstract].

19. Muscatello A, Di Nicola M, Accurti V, et al. Sonoelastography as method for preliminary evaluation of uterine cervix to predict success of induction of labor. Fetal Diagn Ther. 2014;35(1):57-61.

20. Swiatkowska-Freund M, Pankrac Z, Preis K. Intra- and inter-observer variability of evaluation of uterine cervix elastography images during pregnancy. Ginekol Pol. 2014;85(5):360-364.

21. Sabiani L, Haumonte JB, Loundou A, et al. Cervical HI-RTE elastography and pregnancy outcome: a prospective study. Eur J Obstet Gynecol Reprod Biol. 2015;186:80-84.

22. Hee L, Rasmussen CK, Schlütter JM, Sandager P, Uldbjerg N. Quantitative sonoelastography of the uterine cervix prior to induction of labor as a predictor of cervical dilation time. Acta Obstet Gynecol Scand. 2014;93(7):684-690.

23. Fruscalzo A, Mazza E, Feltovich H, Schmitz R. Cervical elastography during pregnancy: a critical review of current approaches with a focus on controversies and limitations. J Med Ultrason (2001). 2016;43(4):493-504.

24. Swiatkowska-Freund M, Preis K. Elastography of the uterine cervix: implications for success of induction of labor. Ultrasound Obstet Gynecol. 2011;38(1):52-56.

25. Hernandez-Andrade E, Hassan SS, Ahn H, et al. Evaluation of cervical stiffness during pregnancy using semiquantitative ultrasound elastography. Ultrasound Obstet Gynecol. 2013;41(2):152-161.

26. Fruscalzo A, Schmitz R, Klockenbusch W, Steinhard J. Reliability of cervix elastography in the late first and second trimester of pregnancy. Ultraschall Med. 2012;33(7):E101-E107.

27. Hernandez-Andrade E, Aurioles-Garibay A, Garcia M, et al. Effect of depth on shear-wave elastography estimated in the internal and external cervical os during pregnancy. J Perinat Med. 2014;42(5):549-557.

28. Thomas A. Imaging of the cervix using sonoelastography. Ultrasound Obstet Gynecol. 2006;28(3):356-357.

29. Carlson LC, Feltovich H, Palmeri ML, Dahl JJ, Munoz del Rio A, Hall TJ. Estimation of shear wave speed in the human uterine cervix. Ultrasound Obstet Gynecol. 2014;43(4):452-458. 
30. Huang B, Drehfal LC, Rosado-Mendez IM, et al. Estimation of shear wave speed in the rhesus macaques' uterine cervix. IEEE Trans Ultrason Ferroelectr Freq Control. 2016;63(9):1243-1252.

31. Peralta L, Mourier E, Richard C, et al. In vivo evaluation of cervical stiffness evolution during induced ripening using shear wave elastography, histology and 2 photon excitation microscopy: insight from an animal model. PLoS One. 2015;10(8):e0133377.

32. Peralta L, Molina FS, Melchor J, et al. Transient elastography to assess the cervical ripening during pregnancy: a preliminary study. Ultrashall Med. Epub 2015 Aug 7.

33. Swiatkowska-Freund M, Traczyk-Łoś A, Preis K, Łukaszuk M, Zielińska K. Prognostic value of elastography in predicting premature delivery. Ginekol Pol. 2014;85(3):204-207.

34. Wozniak S, Czuczwar P, Szkodziak P, Milart P, Wozniakowska E, Paszkowski T. Elastography in predicting preterm delivery in asymptomatic, low-risk women: a prospective observational study. $B M C$ Pregnancy Childbirth. 2014;14:238.

35. Woźniak S, Czuczwar P, Szkodziak P, Wrona W, Paszkowski T. Elastography for predicting preterm delivery in patients with short cervical length at 18-22 weeks of gestation: a prospective observational study. Ginekol Pol. 2015;86(6):442-447.

36. Hernandez-Andrade E, Garcia M, Ahn H, et al. Strain at the internal cervical os assessed with quasi-static elastography is associated with the risk of spontaneous preterm delivery at $\leq 34$ weeks of gestation. $J$ Perinat Med. 2015;43(6):657-666.
37. Öcal FD, Çekmez Y, Erdoğdu E, et al. The utility of cervical elastosonography in prediction of cervical insufficiency: cervical elastosonography and cervical insufficiency. J Matern Fetal Neonatal Med. 2015;28(7):812-818.

38. Fruscalzo A, Londero AP, Fröhlich C, Meyer-Wittkopf M, Schmitz R. Quantitative elastography of the cervix for predicting labor induction success. Ultraschall Med. 2015;36(1):65-73.

39. Wozniak S, Czuczwar P, Szkodziak P, Paszkowski T. Usefulness of elastography in predicting the outcome of Foley catheter labour induction. Aust N Z J Obstet Gynaecol. 2015;55(3):245-250.

40. Pereira S, Frick AP, Poon LC, Zamprakou A, Nicolaides KH. Successful induction of labor: prediction by preinduction cervical length, angle of progression and cervical elastography. Ultrasound Obstet Gynecol. 2014;44(4):468-475.

41. Londero AP, Schmitz R, Bertozzi S, Driul L, Fruscalzo A. Diagnostic accuracy of cervical elastography in predicting labor induction success: a systematic review and meta-analysis. J Perinat Med. 2016;44(2): $167-178$.

42. Carlson LC, Romero ST, Palmeri ML, et al. Changes in shear wave speed pre- and post-induction of labor: a feasibility study. Ultrasound Obstet Gynecol. 2015;46(1):93-98.
International Journal of Women's Health

\section{Publish your work in this journal}

The International Journal of Women's Health is an international, peerreviewed open-access journal publishing original research, reports, editorials, reviews and commentaries on all aspects of women's healthcare including gynecology, obstetrics, and breast cancer. The manuscript management system is completely online and includes

\section{Dovepress}

a very quick and fair peer-review system, which is all easy to use. Visit http://www.dovepress.com/testimonials.php to read real quotes from published authors. 